\title{
A Comparative Study on the Photocatalytic Efficiency of ZnO Nanowires Doped by Different Transition Metals*
}

\author{
N. Martin, M. Capochichi-Gnambodoe, M. Le Pivert and Y. Leprince-Wang ${ }^{\dagger}$ \\ Université Paris-Est, ESYCOM, 5 Bd. Descartes, 77454 Marne-la-Vallée Cedex 2, France
}

(Received November 14, 2018; in final form January 11, 2019)

\begin{abstract}
We synthesized transition metal doped $\mathrm{ZnO}$ nanowires by an easy and efficient hydrothermal method using three different metals: iron, silver, and cobalt at different molar percentage $(1 \%, 2 \%$, and $3 \%)$. Scanning electron microscopy showed quite homogeneous $\mathrm{ZnO}$ nanowire arrays for all doped samples. The photocatalytic efficiency was tested by degrading a methyl orange solution. All doped samples showed better efficiency than undoped samples, the most efficient for each dopant being the $\mathrm{ZnO}: \mathrm{Fe} 3 \%$, the $\mathrm{ZnO}: \mathrm{Ag} 2 \%$, and the $\mathrm{ZnO}: \mathrm{Co} 2 \%$. The photocatalytic efficiency enhancement can be attributed to two effects: the reduction of the band-gap energy allowing more photons to be absorbed; and the increase in oxygen vacancies and the dopant ions on the nanowire surface reducing the electron-hole recombination rate.
\end{abstract}

DOI: 10.12693/APhysPolA.135.471

PACS/topics: 68.55.Ln, 81.07.Gf, 92.20.Ny

\section{Introduction}

Drinkable water is a rare resource, with a large amount of indispensable uses. Considering the increase of human population, it is necessary to find new, inexpensive, efficient, and environment-friendly solutions for wastewater treatment.

One of the most efficient solution is the use of nanostructured semiconductor photocatalysts, as they have proven to be able to degrade organic pollutants in wastewater under sunlight $[1,2]$. Among them, $\mathrm{ZnO}$ is one of the most promising material, due to its non-toxic and environment-friendly nature [1-4], its high thermal and chemical stabilities $[1,4]$, and the fact that it can be made from low-cost raw materials [1]. However, major drawbacks for its use in photocatalysis are its high electron-hole recombination rate $[5,6]$ and its high bandgap energy $(\approx 3.37 \mathrm{eV})[1-4]$, solely allowing the use of ultraviolet light, which represents only about $5 \%$ of the solar spectrum $[2,3]$.

One solution to improve the photocatalytic efficiency of $\mathrm{ZnO}$ is the use of various dopant materials, such as rare earth $[1,3]$, transition metals $[1,3]$ or non-metal materials $[2,3]$, incorporated into the nanostructures during the synthesis. Those dopings allow to narrow the band-gap energy [1-3], improving the use of the solar light, thus the photocatalytic efficiency [2].

In this study, we compared the efficiency of three different transition metals used as dopants: iron, silver, and cobalt. All these metals have been demonstrated as able to improve the photocatalytic efficiency of $\mathrm{ZnO}$ [7-14].

*Presented on: 10th International Workshop on Zinc Oxide and Other Oxide Semiconductors, September 11-14, 2018, Warsaw, Poland.

${ }^{\dagger}$ corresponding author; e-mail: yamin.leprince@u-pem.fr
Iron and silver are also known to be non-toxic and environment-friendly materials [15-18], and cobalt is a widely-used dopant [12-14].

The photocatalysis experiments have been performed by degrading methyl orange (MO) on our samples. We chose $\mathrm{MO}$ as a representative dye, as it is a toxic organic dye, often found in industrial waste waters [8]. Furthermore, this dye is one of the most difficult to degrade compared to the common dyes used in the literature such as rhodamine, methylene blue, or acid red 14, etc.

\section{Experimental details}

The samples are synthesized by a simple hydrothermal method, already described in our previous work [19], the main difference being the growth solution, which now contains $1.125 \mathrm{mM}$ of $\mathrm{Zn}\left(\mathrm{NO}_{3}\right)_{2}, 0.5625 \mathrm{mM}$ of HMTA and the appropriate quantity of the doping solution $\left(\mathrm{FeCl}_{3}, \mathrm{AgNO}_{3}\right.$ or $\left.\mathrm{Co}\left(\mathrm{NO}_{3}\right)_{2}\right)$ to obtain a molar percentage of $1 \%, 2 \%$, or $3 \%$ in dopant product.

The photocatalysis experiments are conducted by degrading $0.3 \mu \mathrm{mol}$ of $\mathrm{MO}$ in a $30 \mathrm{~mL}$ solution under a $365 \mathrm{~nm}$ UV irradiation by a Hamamatsu-LC8 UV-lamp (intensity: $4500 \mathrm{~W} / \mathrm{cm}^{2}$ ) for $3 \mathrm{~h}$, with magnetic stirring. The whole process is monitored by UV-vis spectrometry. After each photocatalysis experiment, the samples are rinsed with milli-Q water and annealed in an oven at $350^{\circ} \mathrm{C}$ for $30 \mathrm{~min}$ in order to remove the eventual residue on the sample surface.

\section{Results and discussion}

We synthesized 3 series of 4 samples for each metal: one for every dopant percentage $(1 \%, 2 \%$, and $3 \%)$ and an undoped $\mathrm{ZnO}$ sample. Figure $1 \mathrm{a}-\mathrm{c}$ shows the SEM images of the 1\%-doped samples and Fig. 1d-f shows the associated UV-vis degradation curve over time. All syntheses lead to samples with homogeneous surfaces of 
nanowires (NWs) distributed all over the substrate. The Fe and Co-doped samples show aspect ratios and morphologies similar to those of the undoped samples, with aspect ratios around 14-15, mean diameters of $85 \pm 5 \mathrm{~nm}$ and heights of $1100 \pm 50 \mathrm{~nm}$, whatever the dopant concentration $(1 \%, 2 \%$, or $3 \%)$. The Ag-doped samples, however, exhibited lesser aspect ratios (around 7-10) and an increased dependence on the dopant concentration, as the mean diameters of the NWs increased, ranging from around $80 \pm 5 \mathrm{~nm}$ for the $1 \%$-doped samples to $100 \pm 10 \mathrm{~nm}$ for the $3 \%$-doped samples, and their mean heights decreased, being around $800 \pm 5 \mathrm{~nm}$ for the 1\%-doped samples and $700 \pm 50 \mathrm{~nm}$ for the $3 \%$-doped samples, leading to lesser aspect ratios.
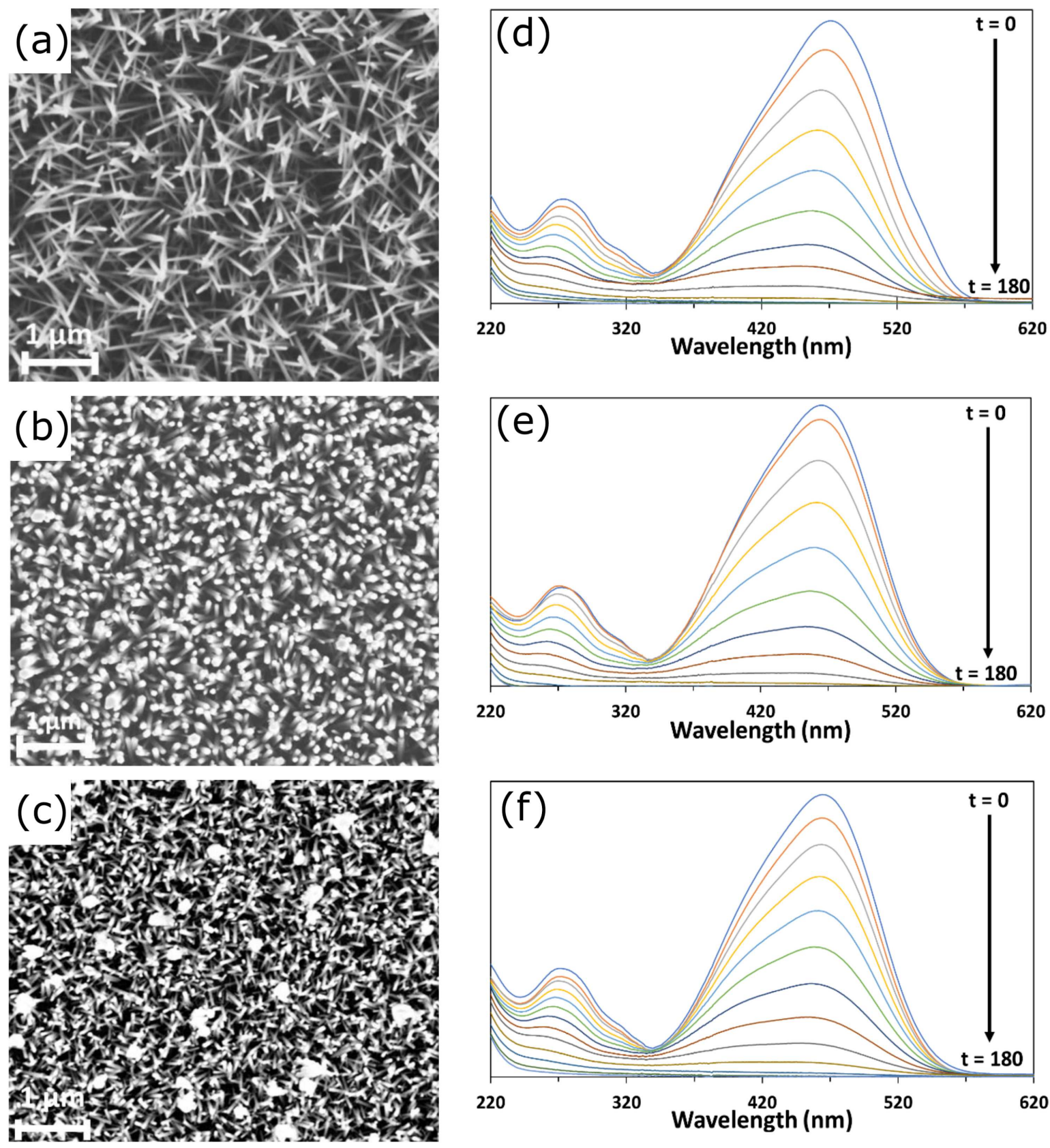

Fig. 1. SEM images and associated UV-vis degradation curves for (a) and (d) ZnO:Fe NWs, (b) and (e) ZnO:Ag NWs, and (c) and (f) ZnO:Co NWs.

The results of the different photocatalysis experiments are presented in Fig. 2a-c, which shows the MO degradation rate over time. Each curve is the mean curve of three photocatalysis using the same sample.
Figure 2a shows the MO photodegradation efficiency results for the Fe-doped $\mathrm{ZnO}$ NWs. All the samples eventually achieve $99 \%$ of MO degradation within $180 \mathrm{~min}$, the $3 \%$-doped sample needing only $120 \mathrm{~min}$ to do so, 

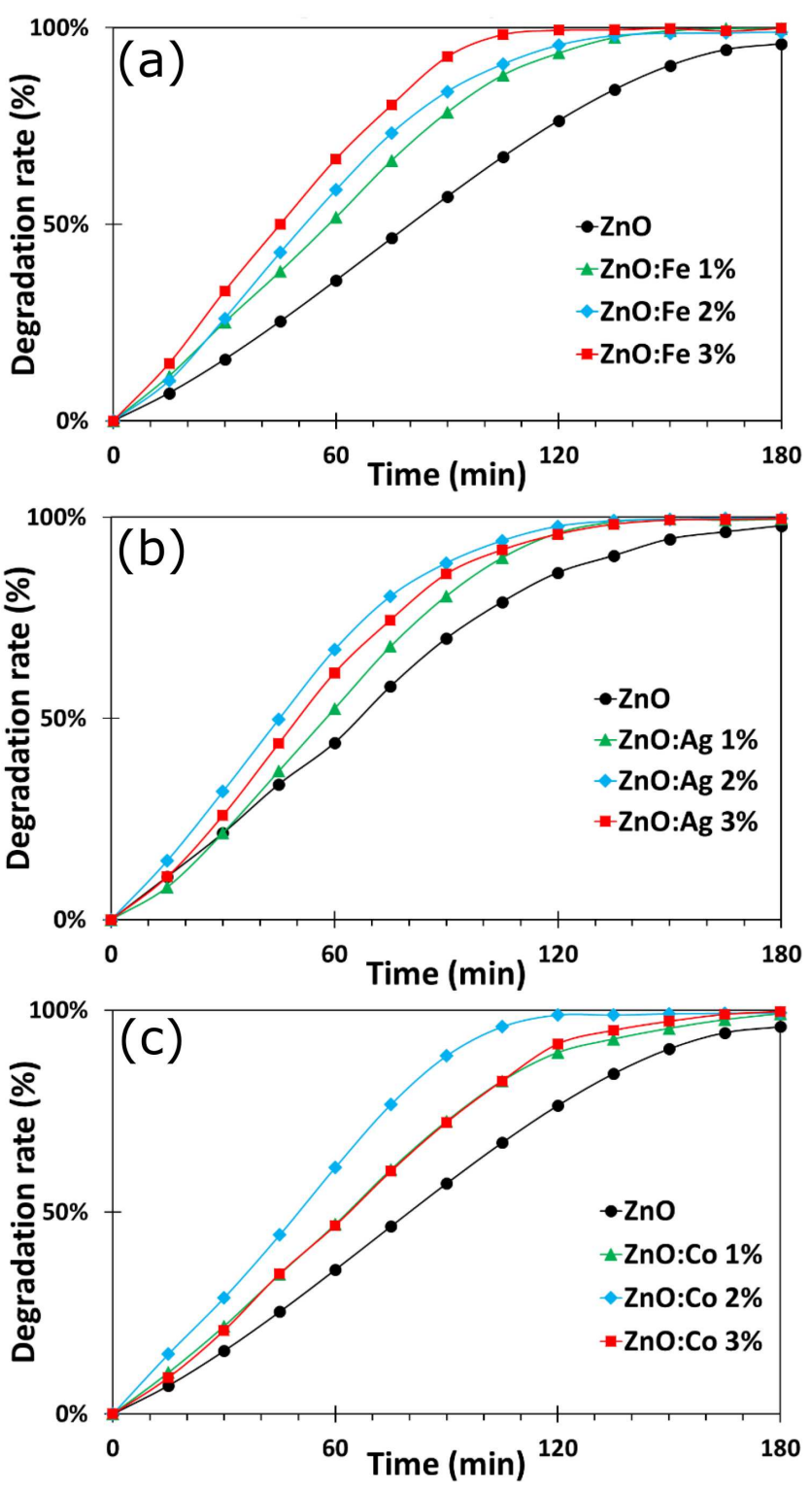

Fig. 2. Photocatalytic efficiency of transition-metaldoped $\mathrm{ZnO}$ : (a) $\mathrm{ZnO}: \mathrm{Fe}$ NWs, (b) $\mathrm{ZnO}: \mathrm{Ag}$ NWs, (c) $\mathrm{ZnO}: \mathrm{Co} N W \mathrm{~s}$.

while the $1 \%$ and $2 \%$ doped samples need about $150 \mathrm{~min}$. Figure $2 \mathrm{~b}$ shows the results for Ag-doped $\mathrm{ZnO}$ NWs. The results of all the different samples are very similar, and they all achieve $99 \%$ degradation in $150 \mathrm{~min}$, the $2 \%$ doped sample being slightly more efficient than the others.

The results shown in Fig. 2c are the results for the Co-doped $\mathrm{ZnO}$ NWs. The $1 \%$ and $3 \%$ doped samples show very similar curves, achieving $99 \%$ degradation after $180 \mathrm{~min}$, while the $2 \%$ doped sample achieves $99 \%$ degradation in 120 min, making it the most efficient. This leads to the hypothesis that there is an optimum in cobalt doping for the photocatalysis efficiency, as the most efficient Co-doping percentage between $2 \%$ and $3 \%$ is still debated [12-14].
As shown by the different results, all the doped samples exhibit a better photocatalytic efficiency than the undoped ones. This is likely due to two different effects of the dopants: the narrowing of the NWs band-gap energy, and the increase in $\mathrm{O}$ vacancies in the NWs structure, creating electron traps, thus reducing the electron-hole recombination rate. To determine which effect was the prominent one, we used the Tauc method to measure the band-gap energy of our samples. For the 1\%,2\%, and $3 \%$ doped samples, the results are, respectively: $3.15,3.05$, and $3.0 \mathrm{eV}$ for $\mathrm{Fe} ; 3.18,3.15$, and $3.11 \mathrm{eV}$ for $\mathrm{Ag}$, and $3.15,3.10$, and $3.10 \mathrm{eV}$ for Co.

The narrowing of the band-gap has already been reported for Fe-doped samples $[7,8]$, and the band-gap energy measurements agree with our iron-doped photocatalysis results. The increase in the $\mathrm{O}$ vacancies has been reported in $\mathrm{Fe}[9,20], \mathrm{Ag}[10,11]$ and $\mathrm{Co}[3,14]$ doped samples, and could explain the differences in the photocatalytic results for Ag- and Co-doped samples, despite their very similar band-gap energies.

We would like to highlight that, for water treatment, we recommend the use of $\mathrm{Fe}$ and $\mathrm{Ag}$, considering their environment-friendly nature. Co has been used here mostly for comparison, but is not an advisable material for use in water.

\section{Conclusion}

We successfully synthesized transition-metal-doped $\mathrm{ZnO}$ nanowires onto wafer Si substrate by an easy hydrothermal method, using only soft conditions. All the samples have exhibited an improvement in the photocatalytic efficiency, being able to fully degrade $\mathrm{MO}$ in $180 \mathrm{~min}$, sometimes less, where undoped $\mathrm{ZnO}$ achieved only $95 \%$ degradation in the same time.

The improvement of the photocatalytic efficiency is mainly due to two different effects: the decrease in bandgap energy, allowing more photons to be absorbed by the photocatalyst, improving the available energy for the reaction, and the increased number of oxygen deficiencies into the nanowires lattices, which act as electron traps, as well as the dopant ions on the surface of the nanowires, decreasing the electron-hole pairs recombination rate. The first effect is the most prominent in the iron-doped samples, the second one being more important for the silver- and cobalt-doped samples.

\section{References}

[1] K.M. Lee, C.W. Lai, K.S. Ngai, J.C. Juan, Water Res. 88, 428 (2016).

[2] W. Yu, J. Zhang, T. Peng Appl. Catal. B Environ. 181, 220 (2016).

[3] S. Rehman, R. Ullah, A.M. Butt, N.D. Gohar, J. Hazard. Mater. 170, 560 (2009).

[4] M. Samadi, M. Zirak, A. Naseri, E. Khorashadizade, A.Z. Moshfegh, Thin Solid Films 605, 2 (2016).

[5] Z. Han, L. Ren, Z. Cui, C. Chen, H. Pan, J. Chen, Appl. Catal. B Environ. 126, 298 (2012). 
[6] F. Sun, X. Qiao, F. Tan, W. Wang, X. Qiu, J. Mater. Sci. 47, 7262 (2012).

[7] Priyanka, V.C. Srivastava, Ind. Eng. Chem. Res. 52, 17790 (2013).

[8] R. Saleh, N.F. Djaja, Superlatt. Microstruct. 74, 217 (2014).

[9] Y. Zhang, M.K. Ram, E.K. Stefanakos, D.Y. Goswami, Surf. Coat. Technol. 217, 119 (2013).

[10] O. Bechambi, M. Chalbi, W. Najjar, S. Sayadi, Appl. Surf. Sci. 347, 414 (2015).

[11] S.M. Hosseini, I.A. Sarsari, J. Alloys Comp. 640, 408 (2015).

[12] A. Sutka, T. Käämbre, R. Pärna, I. Juhnevica, M. Maiorov, U. Joost, V. Kisand, Solid State Sci. 56, 54 (2016)
[13] M.G. Nair, M. Nirmala, K. Rekha, A. Anukaliani, Mater. Lett. 65, 1797 (2011).

[14] Q. Xiao, J. Zhang, C. Xiao, X. Tan, Mater. Sci. Eng. B 142, 121 (2007)

[15] C. Marambio-Jones, E.M.V. Hoek, J. Nanopart. Res. 12, 1531 (2010).

[16] H.T. Ratte, Eviron. Toxicol. Chem. 18, 89 (1999).

[17] B. Szalay, E. Tatrai, G. Nyiro, T. Vezér, G. Dura, J. Appl. Toxicol. 32, 446 (2012).

[18] C. Lei, Y. Sun, D.C.W. Tsang, D. Lin, Environ. Pollut. 232, 10 (2018).

[19] Y.G. Habba, M. Capochichi-Gnambodoe, Y. Leprince-Wang, Appl. Sci. 7, 1185 (2017).

[20] S. Xiao, L. Zhao, J. Lian, Catal. Lett. 144, 347 (2013). 